\title{
Surgical Outcome of Extradural Hematoma Patients in Relation to Preoperative Neurological Status
}

\author{
Reaz A. Howlader ${ }^{1 *}$, Asit C. Sarker², Sukriti Das³, Manirul Islam4, Uzzal K. Sadhukhan², Lima Yasmin ${ }^{1}$ \\ ${ }^{1}$ Department of Neurosurgery, Khulna Medical College, Khulna, Bangladesh \\ ${ }^{2}$ Department of Neurosurgery, Dhaka Medical College, Dhaka, Bangladesh \\ ${ }^{3}$ Department of Neurosurgery, Bangabandhu Sheikh Mujib Medical University (BSMMU), Dhaka, Bangladesh \\ ${ }^{4}$ Department of Neurosurgery, National Institute of Neurosciences \& Hospital Hospital, Dhaka, Bangladesh \\ Email: *reazahmed34@yahoo.com
}

How to cite this paper: Howlader, R.A., Sarker, A.C., Das, S., Islam, M., Sadhukhan, U.K. and Yasmin, L. (2021) Surgical Outcome of Extradural Hematoma Patients in Relation to Preoperative Neurological Status. Open Journal of Modern Neurosurgery, 11, 223-233.

https://doi.org/10.4236/ojmn.2021.114026

Received: April 23, 2021

Accepted: September 15, 2021

Published: September 18, 2021

Copyright $\odot 2021$ by author(s) and Scientific Research Publishing Inc. This work is licensed under the Creative Commons Attribution International License (CC BY 4.0).

http://creativecommons.org/licenses/by/4.0/

\section{(c) (i) Open Access}

\begin{abstract}
Introduction: Epidural hematoma $(\mathrm{EDH})$ is characterized by the acute onset of traumatic haemorrhage into potential space between the dura mater and skull following head injury. About $85 \%$ of the epidural cases are caused by skull fracture with rupture of the middle meningeal artery or its branches and rest of 1the time ruptured venous sinuses, fractured diploic bone. The BTF recommends that all patients with an $\mathrm{EDH}$ volume of greater than $30 \mathrm{cc}$ should undergo surgical evacuation regardless of Glasgow Coma Scale (GCS). Aim of the Study: To assess the surgical outcome of extradural hematoma patients by using Glasgow Outcome Scale (GOS) postoperatively. Material \& Methods: This prospective study was conducted in the Department of Neurosurgery, Dhaka Medical College and Hospital (DMCH), during the period of January 2016 to December 2017. A total of 98 patients of both sex and any age with EDH were selected purposively. Statistical analyses were carried out by using the Statistical Package for Social Sciences version 22.0 for Windows (SPSS Inc., IBM and New York, USA). Prior to commencement of this study, the "Research Review Committee" \& the "Ethical Committee" of DMCH, Dhaka, approved the research protocol. Results: In this study, 98 patients were included; they were divided into 6 groups. Age range was $04-55$ years. It was observed that majority, $30(30.60 \%)$ patients were from 21 - 30 years of age. The mean age was found $25.24 \pm 12.2$ years. Other age related distributions were shown in the table. Male patients were 78 (78.55\%) and 22 (22.44\%) patients were female. A male predominance was observed. Among admitting GCS 3-8, 56.25\% patients had unfavorable outcome and $43.25 \%$ had favorable outcome. Admitting GCS 9-13, 2.5\% patients had unfavorable
\end{abstract}


outcome and $97.5 \%$ had favorable outcome. Admitting GCS 14-15, all patients (100.0\%) had favorable outcome. Unfavorable outcome was observed in 9 (9.18\%), 1 (1.00\%) patients who belong 3-8, 9-13 GCS on admission. Mean GCS on admission was found $6.7 \pm 2.44$ score in unfavorable outcome group and $13.45 \pm 2.30$ score in favorable outcome group. Conclusion: This study revealed good surgical outcome in extradural hematoma patients. Preoperative GCS is an important predictor of outcome. Other preoperative neurological statuses like pupillary changes, neurological focal deficit, cranial nerve involvement, plantar reflexes and seizure also influence the surgical outcome.

\section{Keywords}

Epidural Hematoma, Surgical, Outcome, Traumatic, Postoperatively

\section{Introduction}

Epidural hematoma (EDH) is characterized by the acute onset of traumatic haemorrhage into potential space between the dura mater and skull following head injury [1]. About $85 \%$ of the epidural cases are caused by skull fracture with rupture of the middle meningeal artery or its branches and rest of 1 the time ruptured venous sinuses, fractured diploic bone [1] [2] [3] [4]. It is more common in male patients and usually occurs in the younger population because of the adherence of dura in the inner surface of the skull in the elder population [1]. The peak incidence of extradural haematoma (EDH) is in the second decade of life and mean age of patient with EDH in different series is between 20 and 30 years of age [2]. It is reported that one percent of all deaths and 15\% of deaths occurring between 15 and 24 years are secondary to head injury [5]. Traumatic extradural hematoma (EDH) is a neurosurgical emergency and timely surgical intervention for significant EDH is the gold standard [6]. Craniotomy/craniectomy and evacuation of the hematoma is the treatment of choice [5]. Early identification and adequate management depending on the patient's clinical condition, especially in performing definitive surgery before irreversible cerebral damage occurs and the size of EDH is prerequisites for good outcome [7] [8]. The BTF recommends that all patients with an EDH volume of greater than $30 \mathrm{cc}$ should undergo surgical evacuation regardless of Glasgow Coma Scale (GCS) [7] [9] [10]. It is strongly recommended that patients with an acute EDH and GCS $<9$ and anisocoria undergo surgical evacuation as soon as possible [3]. Jeong et al. [11] observed favorable outcome in $86.3 \%, 89.66 \%$ and unfavorable outcome in $13.69 \%, 10.34 \%$ in urban region, rural region respectively. Khan et al. [12] found that the mean Glasgow Coma Scale (GCS) score at presentation was $9.3 \pm 4.4$. At 3 months, follow up 15 patients had a GOS score of five, four patients had a GOS score of four, two patients had a GOS score of 3, while 3 patients had a GOS score of 1 . On univariate analysis, admitting GCS score, patient's age, the time 
from injury to admission and injury to surgery and anisocoric pupils at presentation were significantly associated with the outcome of GOS score. Jeong et al. [11] found older age $(p=0.0003)$, higher degree of brain injury $(p<0.0001)$, cases of surgical EDH $(\mathrm{p}<0.0001)$, time interval from trauma to hospital before 6 hours, and the decreasing pattern of Glasgow Coma Scale (GCS) between and initial and final GCS were strongly associated with outcome.

\section{Methodology and Materials}

This prospective study was conducted in the Department of Neurosurgery, Dhaka Medical College and Hospital (DMCH), during the period of January 2016 to December 2017. A total of 98 patients of both sex and any age with EDH were selected purposively as inclusion and exclusion criteria. Preoperative computed tomography (CT) scan of brain was obtained for all patients where hyper-dense lentiform lesion under skull was identified as a case of extradural hematoma (EDH). After confirming diagnosis rapid thorough general and neurological examination was done and vital signs including GCS score, pupil status, $\mathrm{BP}$, heart rate, $\mathrm{O}_{2}$ saturation etc. were assessed and documented. CT scan finding including site of hematoma, thickness of hematoma, any midline shifting, underlying brain injury, overlying skull fracture also was assessed and documented. Then rapid resuscitation was done and patient was taken to OT for surgical intervention as early as possible in the form of craniectomy or craniotomy with evacuation of hematoma on the basis of the location of hematoma. Post operatively patient was kept in intensive care unit or post-operative ward. Patient follow-up was carried out for a total of 1 month post-operatively. Follow-up of the patients was done on indoor basis up to discharge and on OPD at 1 month. During follow up the patients were assessed using the post-operative GCS, check CT and Glasgow Outcome Scale (GOS) graded with a five-point score. The researcher himself collected the data. Statistical analyses were carried out by using the Statistical Package for Social Sciences version 22.0 for Windows (SPSS Inc., IBM and New York, USA). Prior to commencement of this study, the "Research Review Committee" \& the "Ethical Committee" of DMCH, Dhaka, approved the research protocol.

\section{- Inclusion Criteria}

o Extradural hematoma patients who were admitted into DMCH of any age and sex.

o Extradural hematoma patients who were treated surgically.

\section{- Exclusion Criteria}

o Posterior fossa extradural hematoma patients.

o Extradural hematoma patient treated conservatively.

\section{Results}

In this study, 98 patients were included; they were divided into 6 groups. Age range was 04 - 55 years. It was observed that majority, 30 (30.60\%) patients were 
from 21 - 30 years of age. The mean age was found $25.24 \pm 12.2$ years. Other age related distributions were shown in the table (Table 1). Male patients were 78 (78.55\%) and $22(22.44 \%)$ patients were female. A male predominance was observed (Table 2). Majority were suffering from motor vehicle accident 44 (44.90\%), 29 (29.60\%) were suffering from assault, 20 (20.40\%) patients were fallen from height and other $04(04.0 \%)$ patients had history of fall of heavy wt. overhead (Table 3). It was observed that majority 25 (25.50\%) patients were had parietal lobe involvement. Other results were shown in the table (Table 4). It was observed that almost two third $65(66.32 \%)$ patients underwent surgery within 6 - 24 hours and 25 (27.50\%) patients were within 24 - 72 hrs (Table 5). GOS of the study patients, it was observed that majority had good recovery during discharge and 1 month after follow up (Table 6). The mean age was found $29.86 \pm 20.23$ years unfavorable outcome group and $24.65 \pm 16.86$ years in

Table 1. Distribution of the study patients by age $(n=98)$.

\begin{tabular}{ccc}
\hline Age in years & Frequency $(\mathrm{n})$ & Percentage (\%) \\
\hline$\leq 10$ & 18 & 18.36 \\
$11-20$ & 24 & 24.48 \\
$21-30$ & 30 & 30.60 \\
$31-40$ & 16 & 16.36 \\
$41-50$ & 8 & 8.16 \\
$51-60$ & 2 & 2.04 \\
Total & 98 & 100.0 \\
& Mean \pm SD 25.24 \pm 12.2 & \\
\hline
\end{tabular}

Table 2. Distribution of the study patients by sex $(n=98)$.

\begin{tabular}{ccc}
\hline & \multicolumn{3}{c}{ study patients $(\mathrm{n}=100)$} \\
\cline { 2 - 3 } Sex & $\mathrm{n}$ & $\%$ \\
\hline Male & 76 & 77.55 \\
Female & 22 & 22.44 \\
Total & 98 & 100.0 \\
\hline
\end{tabular}

Table 3. Distribution of the study patients by mode of injury $(n=98)$.

\begin{tabular}{ccc}
\hline Mode of injury & Frequency (n) & Percentage (\%) \\
\hline Motor vehicle accident & 44 & 44.90 \\
Assault & 29 & 29.60 \\
Fall from height & 20 & 20.40 \\
Fall of heavy wt. over head & 4 & 4.08 \\
Unknown & 1 & 1.01 \\
Total & 98 & 100.0 \\
\hline
\end{tabular}


Table 4. Distribution of the study patients by location of hematoma $(n=98)$.

\begin{tabular}{ccc}
\hline Location of hematoma & Frequency $(\mathrm{n})$ & Percentage $(\%)$ \\
\hline Frontal & 23 & 23.46 \\
Parietal & 25 & 25.50 \\
Temporal & 5 & 5.10 \\
Occipital & 4 & 4.08 \\
Temporo-parietal & 24 & 24.48 \\
Fronto-parietal & 13 & 13.26 \\
Parieto-occipital & 4 & 4.08 \\
Total & 98 & 100.0 \\
\hline
\end{tabular}

Table 5. Distribution of the study patients by timing of operation $(n=98)$.

\begin{tabular}{ccc}
\hline \multirow{2}{*}{ Timing of operation } & \multicolumn{3}{c}{ Frequency $(\mathrm{n}=98)$} \\
\cline { 2 - 3 } & $\mathrm{N}$ & $\%$ \\
\hline within 6 hours & 3 & 3.06 \\
within $6-24$ hours & 65 & 66.32 \\
within $24-72$ hours & 25 & 25.50 \\
$>72$ hour & 5 & 5.10 \\
Total & 98 & 100.0 \\
\hline
\end{tabular}

Table 6. Distribution of the study patients by GOS score $(n=98)$.

\begin{tabular}{cccccc}
\hline \multirow{2}{*}{ GOS score } & \multicolumn{2}{c}{ Frequency $(\mathrm{n}=98)$} & & Outcome \\
\cline { 2 - 6 } & $\mathrm{N}$ & $\%$ & $\mathrm{~N}$ & $\%$ \\
\hline During discharge & & & & \\
1 & 3 & 3.06 & Unfavourable & 13 & 13.26 \\
2 & 1 & 1.01 & Favourable & 85 & 86.73 \\
3 & 9 & 9.18 & & & \\
4 & 30 & 30.60 & & & \\
5 & 55 & 56.12 & & & \\
At 01 month follow & & & & 10 & 10.20 \\
1 & 0 & 0.00 & Unfavourable & & \\
2 & 1 & 1.01 & Favourable & 86.75 \\
3 & 6 & 6.12 & Lost F/U & 2 & 2.04 \\
4 & 11 & 11.22 & & & \\
5 & 75 & 76.53 & & & \\
\hline
\end{tabular}

favorable outcome group (Table 7). Among male patients, 91.02\% had favorable outcome, among female favorable outcome in $72.27 \%$ patients (Table 8). Unfavorable outcome was observed in 9 (9.18\%), 1 (1.00\%) patients who belong 3-8, 9-13 GCS on admission. Mean GCS on admission was found $6.9 \pm 2.34$ score in unfavorable outcome group and $13.23 \pm 2.10$ score in favorable outcome group (Table 9(a)). Among admitting GCS 3-8, 56.25\% patients had unfavorable outcome $43.25 \%$ had favorable outcome. Admitting GCS 9-13, 2.5\% patients had unfavorable outcome $97.5 \%$ had favorable outcome. Admitting GCS 14-15, all patients (100.0\%) had favorable outcome (Table 9(b)). Unfavorable outcome 
Table 7. Association between Glasgow outcome with age $(n=98)$.

\begin{tabular}{|c|c|c|c|c|c|}
\hline \multirow{3}{*}{ Age (in years) } & \multicolumn{4}{|c|}{ Glasgow outcome } & \multirow{3}{*}{$P$ value } \\
\hline & \multicolumn{2}{|c|}{$\begin{array}{l}\text { Unfavorable outcome } \\
\qquad(\mathrm{n}=10)\end{array}$} & \multicolumn{2}{|c|}{$\begin{array}{l}\text { Favorable outcome } \\
\qquad(\mathrm{n}=86)\end{array}$} & \\
\hline & $\mathrm{N}$ & $\%$ & $\mathrm{~N}$ & $\%$ & \\
\hline $0-10$ & 2 & 2.04 & 17 & 17.34 & \multirow{8}{*}{$0.689^{\mathrm{ns}}$} \\
\hline $11-20$ & 3 & 3.06 & 18 & 18.36 & \\
\hline $21-30$ & 3 & 3.06 & 27 & 27.54 & \\
\hline $31-40$ & 2 & 2.04 & 16 & 16.32 & \\
\hline $41-50$ & 3 & 3.06 & 7 & 7.14 & \\
\hline $51-60$ & 1 & 1.01 & 2 & 2.04 & \\
\hline Mean \pm SD & 29.86 & \pm 20.23 & 24.65 & \pm 16.86 & \\
\hline Range (min, max) & $48(4.52)$ & & $51(4.55)$ & & \\
\hline \multicolumn{6}{|c|}{$\mathrm{ns}=$ not significant } \\
\hline
\end{tabular}

Table 8. Association between Glasgow outcome with sex $(n=98)$.

\begin{tabular}{|c|c|c|c|c|c|}
\hline \multirow{3}{*}{ Sex } & \multicolumn{4}{|c|}{ Glasgow outcome } & \multirow{3}{*}{$\mathrm{P}$ value } \\
\hline & \multicolumn{2}{|c|}{$\begin{array}{l}\text { Unfavorable outcome } \\
\qquad(\mathrm{n}=10)\end{array}$} & \multicolumn{2}{|c|}{$\begin{array}{l}\text { Favorable outcome } \\
\qquad(\mathrm{n}=86)\end{array}$} & \\
\hline & $\mathrm{N}$ & $\%$ & $\mathrm{~N}$ & $\%$ & \\
\hline Male & 6 & $8.97 \%$ & 69 & 91.02 & \multirow{2}{*}{$0.611^{\mathrm{ns}}$} \\
\hline Female & 4 & $27.27 \%$ & 17 & 72.72 & \\
\hline \multicolumn{6}{|c|}{ ns $=$ not significant } \\
\hline \multicolumn{6}{|c|}{$P$ value reached from unpaired t-test } \\
\hline
\end{tabular}

Table 9. Association between final Glasgow outcome with GCS on admission ( $\mathrm{n}=98)$.

(a)

\begin{tabular}{|c|c|c|c|c|c|}
\hline \multirow{3}{*}{$\begin{array}{c}\text { GCS on } \\
\text { admission }\end{array}$} & \multicolumn{4}{|c|}{ Outcome } & \multirow{3}{*}{$\mathrm{P}$ value } \\
\hline & \multicolumn{2}{|c|}{ Unfavorable outcome $(\mathrm{n}=10)$} & \multicolumn{2}{|c|}{ Favorable outcome $(\mathrm{n}=86)$} & \\
\hline & $\mathrm{N}$ & $\%$ & $\mathrm{~N}$ & $\%$ & \\
\hline $3-8$ & 9 & 9.18 & 7 & 7.14 & \multirow{4}{*}{$0.044^{\mathrm{s}}$} \\
\hline $9-13$ & 1 & 1.00 & 39 & 39.78 & \\
\hline $14-15$ & 0 & 0.00 & 40 & 42.80 & \\
\hline Mean \pm SD & $6.9 \pm 2.34$ & & $13.23 \pm 2.1$ & & \\
\hline
\end{tabular}

(b)

\begin{tabular}{|c|c|c|c|c|c|c|c|}
\hline \multirow{3}{*}{ Outcome } & \multicolumn{6}{|c|}{ GCS on admission } & \multirow{3}{*}{$\mathrm{P}$ value } \\
\hline & \multicolumn{2}{|c|}{$3-8$} & \multicolumn{2}{|c|}{$9-13$} & \multicolumn{2}{|c|}{$14-15$} & \\
\hline & $\mathrm{n}$ & $\%$ & $\mathrm{n}$ & $\%$ & $\mathrm{n}$ & $\%$ & \\
\hline Unfavorable outcome & 9 & 56.25 & 1 & 2.5 & 0 & 0.00 & $0.044^{\mathrm{s}}$ \\
\hline Favorable outcome & 7 & 43.75 & 39 & 97.5 & 40 & 100.00 & \\
\hline
\end{tabular}


was observed in 9 (9.18\%), 1 (1.00\%) patients who belong 3-8, 9-13 GCS on admission. Mean GCS on admission was found $6.7 \pm 2.44$ score in unfavorable outcome group and $13.45 \pm 2.30$ score in favorable outcome group (Table 10(a)). Among preoperative GCS 3-8, 42.85\% patients had unfavorable outcome $57.14 \%$ had favorable outcome. Admitting GCS 9-13, 2.56\% patients had unfavorable outcome $97.44 \%$ had favorable outcome. Admitting GCS 14-15, all patients $(100.0 \%)$ had favorable outcome (Table 10(b)). Headache in unfavorable outcome patients had $2(3.27 \%)$ and $58(96.73 \%)$ in favorable outcome. Patients had ALC/LOC in unfavorable outcome 12 (17.56\%) and 60 (82.43\%) in favorable outcome. Patients had focal neurological deficit in unfavorable outcome 4 $(100.00 \%)$. Patients had convulsion in unfavorable outcome $3(100.00 \%)$. Patients had pupillary changes in unfavorable outcome 9 (75.00\%) and $3(25.00 \%)$ in favorable outcome. Patients had cranial nerve involvement in unfavorable outcome $10(76.92 \%)$ and $3(23.08 \%)$ in favorable outcome and 11 (68.75\%) patients had plantar extensor in unfavorable outcome and $5(31.25 \%)$ in favorable outcome which were statistically significant $(\mathrm{p}<0.05)$ but other clinical manifestation were not statistically significant $(\mathrm{p}>0.05)$ between two groups (Table 11).

\section{Discussion}

In this present study it was observed that the incidence of $\mathrm{EDH}$ is highest (30.60\%) in the third decade of life ( 21 to 30 years), followed by $2^{\text {nd }}$ decade of life (11 - 20 years) with a mean age of $25.24 \pm 12.2$ years and range from 4 to 55 years which is similarly observed by Khaled et al. [13]. In another study, Emejulu et al. [7] observed the peak age incidence was 21 to 30 years (42\%), with a mean

Table 10. Association between Glasgow outcome with preoperative GCS $(n=98)$.

(a)

\begin{tabular}{|c|c|c|c|c|c|}
\hline \multirow{3}{*}{ Preoperative GCS } & \multicolumn{4}{|c|}{ Glasgow outcome } & \multirow{3}{*}{$P$ value } \\
\hline & \multicolumn{2}{|c|}{$\begin{array}{l}\text { Unfavorable outcome } \\
\qquad(\mathrm{n}=10)\end{array}$} & \multicolumn{2}{|c|}{$\begin{array}{l}\text { Favorable outcome } \\
\qquad(\mathrm{n}=86)\end{array}$} & \\
\hline & $\mathrm{N}$ & $\%$ & $\mathrm{~N}$ & $\%$ & \\
\hline $3-8$ & 9 & 9.18 & 10 & 10.10 & \multirow{4}{*}{$0.041^{\mathrm{s}}$} \\
\hline $9-13$ & 1 & 1.00 & 38 & 38.76 & \\
\hline $14-15$ & 0 & 0.00 & 38 & 38.76 & \\
\hline Mean \pm SD & $6.7 \pm 2.44$ & & $13.45 \pm$ & & \\
\hline
\end{tabular}

(b)

\begin{tabular}{|c|c|c|c|c|c|c|c|}
\hline \multirow{3}{*}{ Outcome } & \multicolumn{6}{|c|}{ Preoperative GCS } & \multirow{3}{*}{$P$ value } \\
\hline & \multicolumn{2}{|c|}{$3-8$} & \multicolumn{2}{|c|}{$9-13$} & \multicolumn{2}{|c|}{$14-15$} & \\
\hline & $\mathrm{n}$ & $\%$ & $\mathrm{n}$ & $\%$ & $\mathrm{n}$ & $\%$ & \\
\hline Unfavorable outcome & 9 & 42.85 & 1 & 2.56 & 0 & 0.00 & $0.041^{\mathrm{s}}$ \\
\hline Favorable outcome & 10 & 57.14 & 38 & 97.44 & 38 & 100.00 & \\
\hline
\end{tabular}


Table 11. Association between Glasgow outcome with clinical manifestation $(n=98)$.

\begin{tabular}{cccccc}
\hline & \multicolumn{4}{c}{ Glasgow outcome } \\
\cline { 2 - 4 } Clinical manifestation & $\begin{array}{c}\text { Unfavorable outcome } \\
(\mathrm{n}=10)\end{array}$ & $\begin{array}{c}\text { Favorable outcome } \\
(\mathrm{n}=86)\end{array}$ & \multirow{2}{*}{ P value } \\
\cline { 2 - 4 } & $\mathrm{N}$ & $\%$ & $\mathrm{~N}$ & $\%$ & \\
\cline { 2 - 4 } Headache & 2 & 3.27 & 58 & 96.73 & $0.03^{\mathrm{s}}$ \\
ALC/LOC & 12 & 17.56 & 60 & 82.43 & $0.114^{\mathrm{ns}}$ \\
Vomiting & 11 & 15.48 & 71 & 84.52 & $0.777^{\mathrm{ns}}$ \\
Lucid interval & 0 & 0.00 & 19 & 100.00 & $0.436^{\mathrm{ns}}$ \\
Focal neurological deficit & 4 & 100.00 & 0 & 0.00 & $<0.001^{\mathrm{s}}$ \\
Convulsion & 3 & 100.00 & 0 & 0.00 & $<0.001^{\mathrm{s}}$ \\
Pupillary changes & 9 & 75.00 & 3 & 25.00 & $0.001^{\mathrm{s}}$ \\
Cranial nerve involvement & 10 & 76.92 & 3 & 23.08 & $0.001^{\mathrm{s}}$ \\
Plantar extensor & 11 & 68.75 & 5 & 31.25 & $0.001^{\mathrm{s}}$ \\
\hline
\end{tabular}

age of 23 years. In this current study, among the 98 patients, it was observed that majority, $76(77.55 \%)$ patients were male and $22(22.44 \%)$ patients were female. Male-female ratio was 3.45:1. A male predominance was observed which reflects male are more exposed to outside world. In one case series in Hong Kong Cheung et al. [6] observed male predominance (78.7\%). Similar observations regarding the male predominant were also observed by Aurangzeb et al. [5], Cheung et al. [6], Emejulu et al. [7], Husain et al. [14], Khaled et al. [13] and Soon et al. [9]. Among the 98 patients it was observed that in majority cases the mode of injury was motor vehicle accident $44(44.88 \%)$ followed by assault 29 (29.58\%) and fall from height $20(20.40 \%)$. In this study, motor vehicle accident was the commonest cause of injury comparable with many other published series Aurangzeb et al. [5]; Cheung et al. [6]; Emejulu et al. [7]; Gurer et al. [15]; Khaled et al. [13]. Location of hematoma was $25.50 \%$ in parietal, $23.46 \%$ in frontal, $24.48 \%$ in temporoparietal, $13.26 \%$ in frontoparietal region and only $2 \%$ in posterior fossa. Hematoma location was parietal in $49 \%$, frontal in $36 \%$, temporal in $10 \%$ and occipital in only $5 \%$ observed by Gerlach et al. [8]. In another study of 610 cases of EDH, temporo-parietal site was involved in $33.45 \%$ ( $\mathrm{n}=$ $204)$ followed by frontal region in $23.28 \%(\mathrm{n}=142)$ and six patients $(0.98 \%)$ had EDH in posterior fossa [13]. Almost two third 65 (66.310\%) patients underwent surgery within 6 - 24 hours of trauma and 25 (25.50\%) patients were within 24 72 hours that was inconsistent with other previous studies. Gerlach et al. [8] found mean time to surgery 19.9 hours, however $53.8 \%$ patients underwent surgical evacuation of hematoma within 6 hours Khaled et al. [13] found that time interval between trauma and surgery was within 13 to 24 hours in maximum (54\%) cases. In this present study it was observed that more than half (56.10\%) of the patients were in Glasgow outcome scale 5 followed by $30.60 \%$ had Glasgow outcome score 4 scale, $9.18 \%$ with scale 3, $1 \%$ with GOS score 2 and $3 \%$ 
with GOS score 1 resulting in favorable outcome in $86.73 \%$ and unfavorable outcome in $13.26 \%$ patients during discharge. At one month two patients lost follow up, 76.5\% patients had GOS 5, 11.22\% patients had GOS 4, 5.10\% patients had GOS 3, 1\% patients had GOS 2 resulting in final favorable outcome in $87.75 \%$ and unfavorable outcome in $10.20 \%$. Cheung et al. [6] observed $73.3 \%$ in GOS 5, 7.8\% in GOS 4, 6.7\% in GOS 3, $1.1 \%$ in GOS 2 and $10.1 \%$ in GOS 1. Gerlach et al. [8] observed excellent outcome (GOS 5) in $89.5 \%$ and good outcome (GOS 4) in $10.5 \%$ cases. In this study, it was observed that almost one-fourth (27.27.0 percentage) patients who had favorable outcome were belonged to age $21-30$ years. The mean age was found $29.86 \pm 20.23$ years unfavorable outcome group and $24.65 \pm 16.86$ years in favorable outcome group. The mean age difference was not statistically significant $(\mathrm{p}=0.689)$ between two groups. Similarly, Gurer B et al. [15] and Khan et al. [12] did not find significant difference between age and functional outcome. Among male patients, 91.02\% had favorable outcome, among female favorable outcome in $72.27 \%$ patients. The sex difference was not statistically significant $(\mathrm{p}=0.611)$ between two groups. Glasgow coma scale (GCS) score at presentation was found significant determinant of outcome. In this study unfavorable outcome was observed in 9 (9.18\%), 1 (1.01\%), 0.0\% patients who belong 3-8, 9-13, 14-15 GCS during admission and preoperatively. Favorable outcome was found $7.14 \%$ in GCS 3-8, $39.78 \%$ in GCS in $9-13,42.84 \%$ in GCS in $14-15$ during admission and $10.2 \%$ in GCS $3-8,38.76 \%$ in GCS $9-13,38 \%$ in GCS $14-15$ preoperatively. Among admitting GCS $3-8,56.25 \%$ patients had unfavorable outcome $43.25 \%$ had favorable outcome. Admitting GCS 9-13, 2.5\% patients had unfavorable outcome 97.5\% had favorable outcome. Admitting GCS 14-15, all patients (100.0\%) had favorable outcome. Mean GCS on admission was found $6.9 \pm 2.34$ score in unfavorable outcome group, $13.23 \pm 2.10$ score in favorable outcome group and $6.7 \pm 2.44$ score in unfavorable outcome group, $13.45 \pm 2.30$ score in favorable outcome group at preoperatively which were statistically significant $(\mathrm{p}=0.044,0.041))$ between two groups that indicate GCS (during admission and preoperatively) highly prognostic of outcome. Cheung et al. [6] observed unfavorable outcome $12.3 \%, 2.2 \%, 3.3 \%$ in GCS $3-8,9-12,13-15$ and favorable outcome in $7.8 \%, 7.8 \%$, 65.6\% in GCS 3-8, 9-12, 13-15. Emejulu et al. [7] observed unfavorable outcome $10.6 \%, 2.1 \%, 2.1 \%$ in GCS $3-8,9-12,13-15$ and favorable outcome in $10.6 \%$, $29.8 \%$ and $44.7 \%$ in GCS 3-8, 9-12, 13-15 that was similar with this study. Gurer B et al. [15] observed that mortality and unfavorable outcome were highly correlated with admitting GCS $(\mathrm{p}<0.001)$. Khan et al. [12], Pruthi et al. [16] and Kang et al. [17] found that admitting GCS was highly prognostic of outcome. In this study $2(3.27 \%)$ patients had headache in unfavorable outcome and 58 (96.73\%) in favorable outcome, $4(100.00 \%)$ patients with focal neurological deficit had unfavorable outcome, $3(100.00 \%)$ patients had convulsion in unfavorable outcome, $9(75.00 \%)$ patients had pupillary changes in unfavorable outcome and $3(25.00 \%)$ in favorable outcome. Clinical manifestations like vomiting, 
ALC/LOC, lucid interval were not statistically significant $(\mathrm{p}>0.05)$ between two groups. Gurer B et al. [15] observed that who had bilateral unreactive pupils before surgery had significantly higher mortality $(\mathrm{p}<0.001)$ and unfavorable outcome ( $\mathrm{p}=0.009)$. Jones et al. [18] and Khan et al. [12] observed that anisocoric pupils at presentation were related to significantly worse outcome with no significant relation between lucid interval and outcome.

\section{Limitations of the Study}

The study population was selected from one selected hospital in Dhaka city, so that the results of the study may not reflect the exact picture of the country. The present study was conducted for a very short period. Small sample size was also a limitation of the present study. Therefore, in future further study should be undertaken with large sample size. Follow up after discharge was short

\section{Conclusion and Recommendation}

This study revealed good surgical outcome in extradural hematoma patients. Preoperative GCS is an important predictor of outcome. Other preoperative neurological statuses like pupillary changes, neurological focal deficit, cranial nerve involvement, plantar reflexes and seizure also influence the surgical outcome. A long follow up study should be done. Study should be done with large sample size. Study should be done at multiple centers.

\section{Conflicts of Interest}

None declared.

\section{References}

[1] Bir, S.C., Maiti, T.K., Ambekar, S. and Nanda, A. (2015) Incidence, Hospital Costs and In-Hospital Mortality Rates of Epidural Hematoma in the United States. Clinical Neurology and Neurosurgery, 138, 99-103. https://doi.org/10.1016/j.clineuro.2015.07.021

[2] Junior, J.F., Andrade, A.F., Yeng, L.C., Koterba, E., Figueiredo, E.G.D., Guilherme Lepski, G., et al. (2016) Epidural Hematoma: A Prospective Analysis of Morbidity and Mortality in 173 Patients. Arquivos Brasileiros de Neurocirurgia, 34, 20-24. https://doi.org/10.1055/s-0035-1547391

[3] Green, M.S. (2016) Handbook of Neurosurgery. 8th Edition, Thieme, New York.

[4] Ramamurthi, T.P.N. (2012) Text Book of Neurosurgery. 3rd Edition, Jaypee Brother's Medical Publishers Ltd., New Delhi.

[5] Aurangzeb, A., Ahmed, E., Maqbool, S., Ihsan, A., Ali, A., Bhatti, S.N., et al. (2016) Burr Hole Evacuation of Extradural Hematoma in Mass Trauma. A Life Saving and Time Saving Procedure: Our Experience in the Earthquake of 2005. Turkish Neurosurgery, 26, 205-208.

[6] Cheung, P.S.Y., Lam, J.M.Y., Yeung, J.H.H., Graham, C.A., Rainer, T.H. (2007) Outcome of Traumatic Extradural Haematoma in Hong Kong. Injury, 38, 76-80. https://doi.org/10.1016/j.injury.2006.08.059

[7] Emejulu, J.K.C., Uche, E.O. and Nwankwo, E.U. (2014) The Challenges of Manag- 
ing Acute Extradural Hematoma in a Nigerian Neurosurgical Center-Still a Long Way to Go. World Neurosurgery, 82, 969-973. https://doi.org/10.1016/j.wneu.2014.09.002

[8] Gerlach, R., Dittrich, S., Schneider, P.W., Ackermann, H., Seifert, V. and Kieslich, M. (2009) Traumatic Epidural Hematomas in Children and Adolescents Outcome Analysis in 39 Consecutive Unselected Cases. Pediatric Emergency Care, 25, 164-169. https://doi.org/10.1097/PEC.0b013e31819a8966

[9] Soon, W.C., Marcus, H. and Wilson, M. (2016) Traumatic Acute Extradural Haematoma-Indications for Surgery Revisite. British Journal of Neurosurgery, 30, 233-234. https://doi.org/10.3109/02688697.2015.1119237

[10] Zakaria, Z., Kaliaperumal, C., Kaar, G., O’Sullivan, M. and Marks, C. (2013) Extradural Haematoma-To Evacuate or Not? Revisiting Treatment Guidelines. Clinical Neurology and Neurosurgery, 115, 1201-1205.

https://doi.org/10.1016/j.clineuro.2013.05.012

[11] Jeong, Y.H., Oh, J.W. and Cho, S. (2016) Clinical Outcome of Acute Epidural Hematoma in Korea: Preliminary Report of 285 Cases Registered in the Korean Trauma Data Bank System. Korean Journal of Neurotrauma, 12, 47-54.

https://doi.org/10.13004/kjnt.2016.12.2.47

[12] Khan, M.B., Riaz, M., Javed, G., Hashmi, F.A., Sanaullah, M. and Ahmed, S.I. (2013) Surgical Management of Traumatic Extra Dural Hematoma in Children: Experiences and Analysis from 24 Consecutively Treated Patients in a Developing Country. Surgical Neurology International, 4, Article No. 103. https://doi.org/10.4103/2152-7806.116425

[13] Khaled, C.N., Raihan, M.Z., Chowdhury, F.H., Ashadullah, A.T.M., Sarkar, M.H. and Hossain, S.S. (2008) Surgical Management of Traumatic Extradural Haematoma: Experiences with 610 Patients and Prospective Analyses. Indian Journal of Neurotrauma, 5, 75-79. https://doi.org/10.1016/S0973-0508(08)80004-4

[14] Husain, M., Ojha, B.K., Chandra, A., Singh, A., Singh, G., Chugh, A., et al. (2007) Contralateral Motor Deficit in Extradural hematoma: Analysis of 35 Patients. Indian Journal of Neurotrauma, 4, 41-44. https://doi.org/10.1016/S0973-0508(07)80010-4

[15] Gurer, B., Kertmen, H., Yilmaz, E.R., Dolgun, H., Hasturk, A.E. and Sekerci, Z. (2017) The Surgical Outcome of Traumatic Extraaxial Hematomas Causing Brain Herniation. Turkish Neurosurgery, 27, 37-52.

[16] Pruthi, N., Balasubramaniam, A., Chandramouli, B.A., Somanna, S., Devi, B.I., Vasudevan, P.S., et al. (2009) Mixed-Density Extradural Hematomas on Computed Tomography_Prognostic Significance. Surgical Neurology, 71, 202-206. https://doi.org/10.1016/j.surneu.2007.10.032

[17] Kang, J., Hong, S., Hu, C., Pyen, J., Whang, K., Cho, S., et al. (2015) Clinical Analysis of Delayed Surgical Epidural Hematoma. Korean Journal of Neurotrauma, 11, 112-117. https://doi.org/10.13004/kjnt.2015.11.2.112

[18] Jones, N.R., Molloy, C.J., Kloeden, C.N., North, J.B. and Simpson, D.A. (1993) 2009 Extradural Haematoma: Trends in Outcome over 35 Years. British Journal of Neurosurgery, 7, 465-471. https://doi.org/10.3109/02688699308995068 